\title{
Anti-apoptotic, antioxidant and anti-aging effects of 6-shogaol on human dermal fibroblasts
}

\author{
Hyo Sun Han ${ }^{1,2}$, Ki Bbeum Kim², Jin Hyuk Jung ${ }^{2}$, In Sook An², You-Jeong Kim³ and Sungkwan An ${ }^{4^{*}}$ (D
}

\begin{abstract}
Background: 6-Shogaol is a constituent of ginger that imparts the pungent flavor and a hydrolysis product of gingerols. This study aimed to investigate the potential of 6-shogaol as a natural cosmetic raw material by examining its anti-apoptotic, antioxidant, and anti-aging effects in human dermal fibroblasts (HDFs).
\end{abstract}

Methods: Cell cycle analysis, ApoAlert caspase-3 colorimetric assay, and qRT-PCR analysis to assess the anti-apoptotic effects and qRT-PCR to measure the expression of SOD, CAT, and NRF2 to assess the antioxidant effects of 6-shogaol were performed; dichlorofluorescein diacetate was used to measure reactive oxygen species (ROS). Anti-aging effects were examined using qRT-PCR analysis to measure the expression of COLIA1 and MMP1 as well as using an SA-beta Gal assay.

Results: 6-Shogaol showed no toxicity in HDFs at concentrations 5, 10, and $20 \mu \mathrm{M}$, and increased cell viability in a dose-dependent manner. qRT-PCR analysis showed that 6-shogaol pre-treatment downregulated the expression of $B A X$, caspase 3, and caspase 9 in a dose-dependent manner. Sub-G1 cells, which are rarely found in the normal cell cycle, decreased in a concentration-dependent manner after 6-shogaol pre-treatment, and treatment ameliorated the ROS increase observed upon UVA $\left(10 \mathrm{~J} / \mathrm{cm}^{2}\right)$ irradiation of HDFs and the expression of NRF2 increased in a dose-dependent manner. In addition, the expression of SOD and CAT, which are typical cellular antioxidant enzymes, increased. 6-Shogaol also increased the expression of COLIA1, the gene type 1 collagen in HDFs, and decreased the expression of MMP1, which codes for an enzyme that degrades type 1 collagen, thus promoting collagen formation.

Conclusions: These results suggest that 6-shogaol can be used as a cosmetic material for preventing skin aging because of the cytoprotective, anti-apoptotic, and antioxidant effects in the HDFs identified in this study.

Keywords: Human dermal fibroblast, 6-Shogaol, Anti-apoptosis, Antioxidant, Anti-aging

\section{Background}

Ultraviolet rays are one of the most common causes of extrinsic aging and can be divided into UVA, UVB, and UVC depending on their wavelength. UVA, which has a relatively long wavelength range at $320-400 \mathrm{~nm}$, has a lower energy level than UVB but is 20 times more abundant on the earth's surface because it is not easily absorbed in the atmosphere; it can also penetrate the dermal layer (Kim et al. 2011; Piao et al. 2013). Persistent exposure to UVA causes oxidative stress to dermal

\footnotetext{
* Correspondence: ansungkwan@konkuk.ac.kr

${ }^{4}$ Department of Cosmetics Engineering, Konkuk University, 120

Neungdong-ro, Gwangjin-gu, Seoul 05029, Republic of Korea

Full list of author information is available at the end of the article
}

fibroblasts and damage to DNA, lipids, and proteins, ultimately leading to skin aging (Yoon et al. 2013; Cha and Kim 2015). Ginger (Zingiber officinale), which has been used since a long time for its unique pungent flavor and aroma, is also known for its anti-inflammatory, antioxidant, antithrombotic, anti-cancer, and anti-arthritic properties (Kim et al. 2008; Ling et al. 2010). Its major chemical constituents are gingerols, shogaols, and paradols. Gingerols are the most abundant molecules in fresh ginger, and their hydrolysis products are shogaols (Bak et al. 2012; Huang et al. 2014). 6-Shogaol, one of the constituents responsible for its pungent flavor, has attracted interest because of its potential uses in the medical and food fields due to its anti-cancer,

(C) The Author(s). 2018 Open Access This article is distributed under the terms of the Creative Commons Attribution 4.0 International License (http://creativecommons.org/licenses/by/4.0/), which permits unrestricted use, distribution, and 
anti-inflammation, antioxidant, and antibacterial properties. However, there have been no studies on the effects of 6-shogaol in human dermal fibroblasts (HDFs) with respect to its possible use in cosmetics. Furthermore, because of the current aging population and a growing interest in maintaining a friendly environment and safety of raw materials for cosmetics, there is an urgent need to safely develop natural cosmetic raw materials with excellent anti-aging properties. Therefore, this study sought to investigate the potential of 6-shogaol as a natural cosmetic raw material by examining its possible anti-apoptotic, antioxidant, and anti-aging effects in HDFs.

\section{Methods}

\section{Cell culture and sample treatment}

HDFs (Lonza, Switzerland) were cultured in Dulbecco's modified Eagle medium (HyClone ${ }^{\mathrm{Tm}}$, GE Healthcare Life Sciences, UK) containing $10 \%$ fetal bovine serum $\left(\right.$ HyClone $^{\mathrm{Tm}}$ ) and 1\% antibiotics (penicillin $100 \mathrm{IU} / \mathrm{mL}$, streptomycin $100 \mu \mathrm{g} / \mathrm{mL}$; Invitrogen ${ }^{\mathrm{Tx}}$, Thermo Fisher Scientific). Cells were cultured at $37^{\circ} \mathrm{C}$ and in an atmosphere of $5 \% \mathrm{CO}_{2}$.

6-Shogaol was purchased in a powder form (>90\% purity) from Sigma-Aldrich Inc. (St. Louis, MO, USA) and dissolved in dimethyl sulfoxide (Sigma-Aldrich). UVA irradiation was performed using a UV-A lamp (UVP, USA) at a dose of $10 \mathrm{~J} / \mathrm{cm}^{2}$, based on a previous study (Lee et al. 2017).

\section{Cell viability}

The water-soluble tetrazolium salt (WST-1) assay was used to assess cell viability. After seeding HDFs in $100 \mu \mathrm{L}$ at a density of $3 \times 10^{3}$ cells/well in a 96-well plate and culturing for $24 \mathrm{~h}, 6$-shogaol was added at the indicated concentrations, followed by UVA irradiation. $10 \mu \mathrm{L}$ of EZ-Cytox cell viability assay kit reagent (ItsBio, Seoul, Korea) was then added, and the plate was incubated for $1 \mathrm{~h}$ prior to reading absorbance in a microplate reader (Bio-Rad, Hercules, CA, USA) at $490 \mathrm{~nm}$.

\section{Cell cycle analysis}

Cell cycle was analyzed by measuring the cell population in sub G1, G1, S, and G2/M phases using a BD FACSCalibur $^{\text {Tm }}$ flow cytometer (BD Biosciences, San Jose, CA, USA). Cells were seeded into $60-\mathrm{mm}$ culture dishes at $2 \times 10^{5}$ cells/dish, incubated for $24 \mathrm{~h}$, and then pre-treated with 6 -shogaol $(5,10,20 \mu \mathrm{M})$ for $6 \mathrm{~h}$. After UVA irradiation, cells were incubated for $24 \mathrm{~h}$ and then harvested and centrifuged at $5000 \mathrm{rpm}$ for $5 \mathrm{~min}$ at $4{ }^{\circ} \mathrm{C}$. The supernatant was removed, and $300 \mu \mathrm{L}$ of phosphate-buffered saline (PBS) was added to resuspend the cell pellet. Absolute ethanol $(700 \mu \mathrm{L})$ was then gradually added while vortexing. The cells were then fixed by incubating at $4{ }^{\circ} \mathrm{C}$ for at least $3 \mathrm{~h}$, after which $1 \mathrm{~mL}$ PBS was added. After centrifugation at $5000 \mathrm{rpm}$ for $5 \mathrm{~min}$ at $4{ }^{\circ} \mathrm{C}$, the supernatant was removed and the cells were resuspended in $200 \mu \mathrm{L}$ of propidium iodide (PI) staining buffer (Sigma-Aldrich) and incubated at $37^{\circ} \mathrm{C}$ for $1 \mathrm{~h}$.

\section{qRT-PCR}

RNA was extracted using Trizol reagent (Invitrogen/Life Technologies), following the manufacturer's instructions. After addition of $0.2 \mathrm{~mL}$ of chloroform (Biopure, Tulln, Austria) and centrifugation for $20 \mathrm{~min}$ at $12000 \mathrm{rpm}$ and $4{ }^{\circ} \mathrm{C}, 0.5 \mathrm{~mL}$ of isopropanol (Biopure) was added to the supernatant, and the sample was incubated at room temperature for $10 \mathrm{~min}$. The sample was then centrifuged at $12000 \mathrm{rpm}$ and $4{ }^{\circ} \mathrm{C}$, and the RNA pellet was washed with $75 \%$ ethanol and dried at room temperature. RNA was then dissolved in diethylpyrocarbonate (DEPC; Biopure) in water. A Nanodrop spectrophotometer (MaestroGen, Taiwan) was used to measure OD 260/280 nm, and only RNAs with a value $>1.8$ were used. Ten microliters of $1 \mu \mathrm{g}$ RNA, $0.5 \mathrm{ng}$ oligo dT18, and DEPC water in a PCR tube was incubated at $70{ }^{\circ} \mathrm{C}$ for $10 \mathrm{~min}$ to induce RNA denaturation, and this sample was then reverse-transcribed by adding M-MLV reverse transcriptase (Enzynomics, Dajeon, Korea) and incubating for $1 \mathrm{~h}$ at $37^{\circ} \mathrm{C}$. PCR was validated via a melting curve analysis, and the expression of each gene of interest was compared after standardization with respect to the expression of $\beta$-actin. All primers used are listed in Table 1.

\section{Cell senescence}

Cell senescence was assessed using a senescence-associated $\beta$-galactosidase assay (BioVision, Milpitas, CA, USA). HDFs were seeded into $60-\mathrm{mm}$ dishes at $2 \times 10^{5}$ cells/dish, cultured for $24 \mathrm{~h}$, and pre-treated with 6 -shogaol at 5, 10, and $20 \mu \mathrm{M}$ for $6 \mathrm{~h}$. After UVA irradiation, the cells were incubated for a further $24 \mathrm{~h}$. Cells were then removed from the medium, washed with 1 $\mathrm{mL}$ of PBS, and fixed with $0.5 \mathrm{~mL}$ of a fixing solution at room temperature for $15 \mathrm{~min}$. The fixed cells were incubated in $0.5 \mathrm{~mL}$ of staining mixture containing $470 \mu \mathrm{L}$ staining solution, $5 \mu \mathrm{L}$ staining supplement, and $25 \mu \mathrm{L}$ $\mathrm{X}$-gal in dimethylformamide (DMF; $20 \mathrm{mg} / \mathrm{mL}$ ) at $37^{\circ} \mathrm{C}$ for $24 \mathrm{~h}$. Cells were washed with PBS, and the ratio of the number of stained cells to the total was determined by examination using an optical microscope (Olympus, Tokyo, Japan).

\section{ROS measurement}

Dichlorofluorescein diacetate (DCF-DA) was used to measure intracellular reactive oxygen species (ROS) concentrations. HDFs were seeded on $60-\mathrm{mm}$ dishes at $2 \times$ $10^{5}$ cells/dish and cultured for $24 \mathrm{~h}$ before pre-treatment with 6 -shogaol at 5,10 , and $20 \mu \mathrm{M}$ for $6 \mathrm{~h}$. After UVA 
Table 1 Lists of primers used in this study

\begin{tabular}{lll}
\hline Gene & Forward primer & Reverse primer \\
\hline - actin & GGATTCCTATGTGGGCGACGA & CGCTCGGTGAGGATCTTCATG \\
COLIA1 & AGGGCCAAGACGAAGACATC & AGATCACGCATCGCACAACA \\
MMP1 & GGGCTTAGATCATTCCTCAGTGCC CAGGGTACACCAGTGACTGCAC \\
SOD1 & GGGAGATGGCCCAACTACTG & CCAGTTGACATGCAACCGTT \\
CAT & ATGGTCCATGCTCTCAAACC & CAGGTCATCCAATAGGAAGG \\
NRF2 & TACTCCCAGGTTGCCCACA & CATCTACAAACGGGAATGTCTGC \\
BAX & CCCTTTCTACTTTGCCAGCAA & CCCGGAGGAGTCCAATGT \\
Caspase-3 & TTTGAGCCTGAGCAGAGACATG & TACCAGT GCGTATGGAGAAATGG \\
Caspase-9 & CCGTGGACATTGGTTTG & TCTTGGCAGTCAGGTCGTT \\
\hline
\end{tabular}

irradiation, the cells were incubated for $24 \mathrm{~h}$. DCF-DA $(10 \mu \mathrm{M})$ was added and incubated for $30 \mathrm{~min}$. After washing with PBS, cells were released and analyzed by flow cytometry (BD Biosciences) to measure ROS levels. $\mathrm{L}$-ascorbic acid $(20 \mu \mathrm{M})$, which is a ROS scavenger, was used as a positive control and was measured in the same manner to compare the efficacy of ROS removal.

\section{Caspase activity}

The ApoAlert ${ }^{\mathrm{Tm}}$ caspase- 3 colorimetric assay kit (Clontech, USA) was used to assess expression of caspase 3 and caspase 9. HDFs pre-treated with 6-shogaol at the indicated concentrations were isolated and resuspended in chilled cell lysis buffer, incubated on ice for $10 \mathrm{~min}$, and centrifuged at $15,000 \mathrm{rpm}$ for $3 \mathrm{~min}$ at $4{ }^{\circ} \mathrm{C}$. The supernatant was added to a 96-well plate containing ApoAlert ${ }^{\mathrm{Ts}}$ reaction buffer, and the plate was incubated at $37^{\circ} \mathrm{C}$ for 30 min. Caspase substrate was then added before incubation for $1 \mathrm{~h}$ at $37^{\circ} \mathrm{C}$ and measurement of absorbance at 405 nm using a microplate reader (Bio-Rad).

\section{Statistical analysis}

All experiments were separately performed more than three times. Student's $t$ test was used to compare the treatments, and a $p$ value $<0.05$ was considered significant.

\section{Results}

\section{Cytotoxicity and cytoprotectivity}

HDFs were treated with 5, 10, 20, 40, and $80 \mu \mathrm{M}$ 6-shogaol for $6 \mathrm{~h}$ and examined using the WST-1 assay to estimate cytotoxicity. There was little effect on viability at 5-40 $\mu \mathrm{M}$, although a decrease was observed at $80 \mu \mathrm{M}$. These results suggest that 6 -shogaol is not cytotoxic at concentrations $\leq 40 \mu \mathrm{M}$ (Fig. 1a). $10 \mathrm{~J} / \mathrm{cm}^{2} \mathrm{UVA}$ irradiation reduced HDF cell viability to $67 \%$ compared with non-irradiated control. However, 6-shogaol at concentrations of 5,10 , and $20 \mu \mathrm{M}$ increased cell viability to $78 \%, 82 \%$, and $87 \%$, respectively. The cell viability was increased by 6-shogaol pre-treatment in a concentration-dependent manner (Fig. 1b).

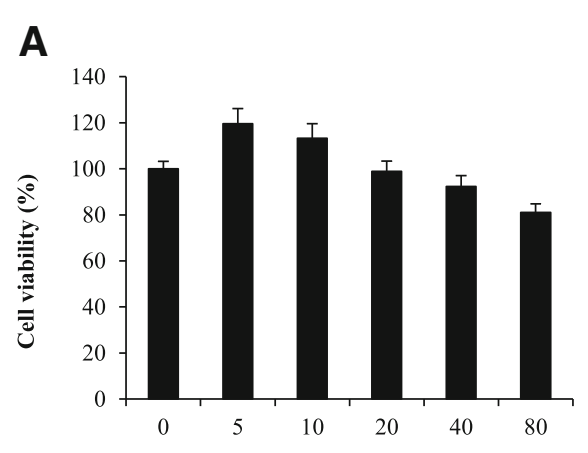

\section{B}

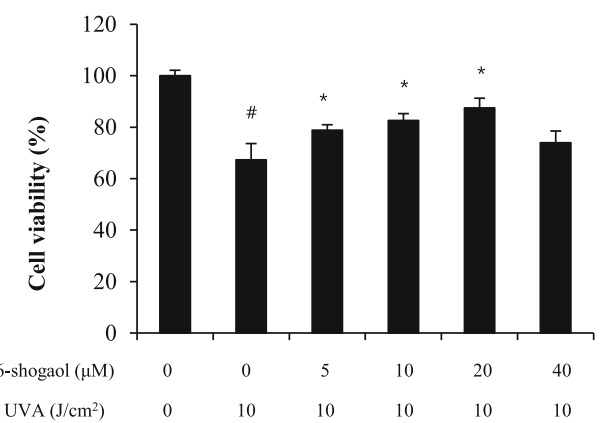

Fig. 1 Effect of 6-shogaol on HDF viability. a 6-Shogaol was non-toxic to HDFs at concentrations of 5, 10, 20, and $40 \mu \mathrm{M}$. b Cell viability of HDFs after UVA irradiation increased upon 6-shogaol treatment in a dose-dependent manner up to $20 \mu \mathrm{M}$. The data represents the mean \pm S.D. of the relative cell viability in each sample from triplicate experiments. Student's $t$ test was conducted to determine statistical significance. ${ }^{*} p<0.05$ compared with UVAirradiated cells without 6-shogaol treatment; $\# p<0.05$ compared with negative controls that were not treated 6-shogaol or UVA irradiation 


\section{Anti-apoptotic effects}

\section{6-Shogaol reduces sub-G1 phase in UVA-irradiated HDFs}

The sub-G1 population of UVA-damaged HDFs increased from 2.1 to $17.9 \%$, but 6 -shogaol at concentrations of 5,10 , and $20 \mu \mathrm{M}$ reduced this to $14.2 \%, 9.6 \%$, and $3.4 \%$, respectively (Fig. 2a). The increase in the number of cells in sub-G1 phase, which is rarely observed in the normal cell cycle, is indicative of increased cell cycle arrest and apoptosis.

\section{6-Shogaol reduces gene expression of BAX in UVA- irradiated HDFs}

Bax is the pro-apoptotic cytoplasmic protein, and its expression was indirectly measured using qRT-PCR. UVA $\left(10 \mathrm{~J} / \mathrm{cm}^{2}\right)$ increased $B A X$ mRNA expression from 0.37 fold to 1 fold. However, 6-shogaol treatment at 5, 10, and $20 \mu \mathrm{M}$ reduced $B A X$ mRNA expression to 0.84 fold, 0.51 fold, and 0.47 fold, respectively (Fig. 2b; Han et al. 2008).

\section{6-Shogaol reduces gene expression of caspase 3 and caspase 9 in UVA-irradiated HDFs}

Expression of caspase 3 and caspase 9, which are proteases involved in apoptosis, was also indirectly measured by qRT-PCR. Caspases 3 and 9 mRNA increased from 1 fold to 2.2 fold and 1.9 fold, respectively, upon $10 \mathrm{~J} / \mathrm{cm}^{2}$ UVA irradiation, but 6 -shogaol at 5,10 , and $20 \mu \mathrm{M}$ reduced this to 2 fold, 1.6 fold, and 1.4 fold for caspase 3 and 1.8 fold, 1.3 fold, and 1.1 fold for caspase 9, respectively (Fig. 2c; Li et al. 1997).

\section{Antioxidant effects}

\section{ROS scavenging}

UVA-irradiated HDFs exhibited an increase in DCF fluorescence intensity, whereas cells pre-treated with 5, 10, and $20 \mu \mathrm{M}$ 6-shogaol exhibited a significantly reduced DCF intensity of $125 \%, 79 \%$, and $61 \%$, respectively. At $20 \mu \mathrm{M}, 6$-shogaol exhibited a similar
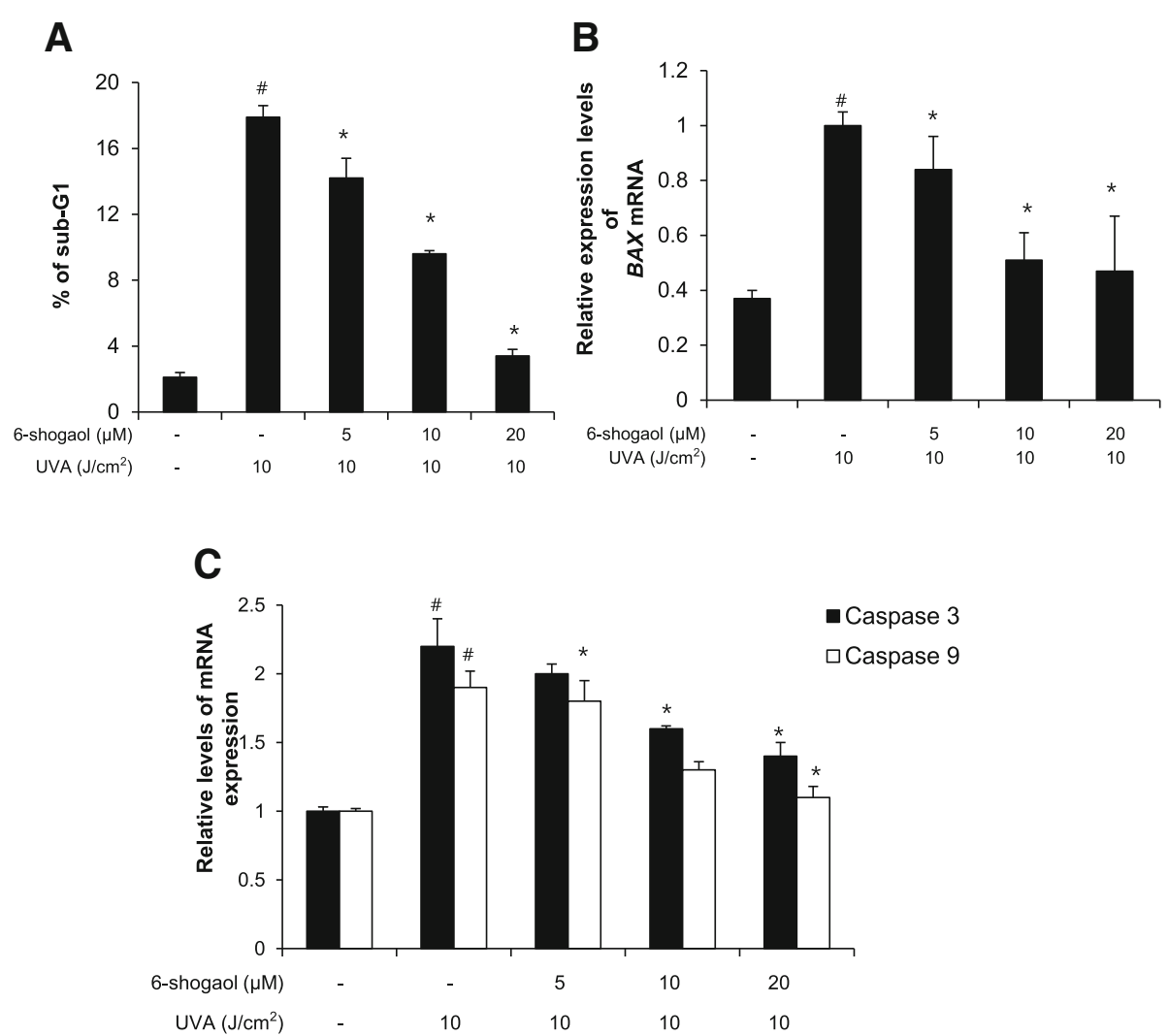

Fig. 2 Anti-apoptotic effect of 6-shogaol in UVA-irradiated HDFs. a Cell cycle phases were determined by the propidium iodide staining and flow cytometry. 6-Shogaol pre-treatment downregulated the number of cells in sub-G1 phase in a dose-dependent manner. b 6-Shogaol pre-treatment downregulated the expression of BAX mRNA in a dose-dependent manner. c 6-Shogaol pretreatment downregulated the expression of caspases 3 and 9 mRNA in a dose-dependent manner. The graphs are combined from three independent experiments (mean \pm S.D.). Student's $t$ test was conducted to determine statistical significance. ${ }^{*} p<0.05$ compared with UVA-irradiated cells without 6-shogaol treatment; $\# p<0.05$ compared with negative controls that were not treated 6-shogaol or UVA irradiation 
radical scavenging ability as that obtained with the same concentration of L-ascorbic acid (69\%), the positive control (Fig. 3a).

\section{6-Shogaol upregulates the gene expression of SOD and CAT in UVA-irradiated HDFs}

$S O D$ and $C A T$ encode representative antioxidant enzymes that reduce oxidative stress, and their expression was assessed by qRT-PCR. $10 \mathrm{~J} / \mathrm{cm}^{2}$ UVA irradiation reduced SOD expression from 100 to 55\%. Treatment with 6-shogaol at 5, 10, and $20 \mu \mathrm{M}$ reduced $S O D$ expression to $61 \%, 77 \%$, and $81 \%$, respectively (Fig. $3 \mathrm{~b}$ ). Similarly, $10 \mathrm{~J} / \mathrm{cm}^{2}$ UVA irradiation reduced CAT expression from 100 to $74 \%$, whereas treatment with 6 -shogaol at 5,10 , and $20 \mu \mathrm{M}$ reduced $C A T$ expression to $80 \%, 93 \%$, and $90 \%$, respectively (Fig. 3c).

\section{6-Shogaol upregulates the gene expression of NRF2 in UVA-} irradiated HDFs

NRF2 is a transcription factor that regulates the expression of antioxidant enzymes in response to oxidative stress. $10 \mathrm{~J} / \mathrm{cm}^{2}$ UVA irradiation reduced NRF2 expression from 100 to $53 \%$. In the presence of 6-shogaol, the reduction was only $63 \%$ at $5 \mu \mathrm{M}$, whereas there was an increase to $114 \%$ and $179 \%$, respectively, at 10 and $20 \mu \mathrm{M}$ (Fig. 3d).

\section{Anti-aging effects \\ 6-Shogaol reduces cellular senescence in HDFs}

The senescence-associated $\beta$-galactosidase (SA- $\beta$-gal) assay was used to assess cellular senescence, and $10 \mathrm{~J} /$ $\mathrm{cm}^{2}$ UVA irradiation increased the expression ratio of SA- $\beta$-gal to 7.9 fold (79\%) over control cells (10\%). However, the ratio of SA- $\beta$-gal decreased in a concentration-dependent manner to $68 \%$ at $5 \mu \mathrm{M}$ 6-shogaol, 38\% at $10 \mu \mathrm{M}$ 6-shogaol, and 31\% at $20 \mu \mathrm{M}$ 6-shogaol, indicating that 6-shogaol can suppress cellular senescence induced by UVA irradiation (Fig. 4a).

\section{6-Shogaol regulates the gene expression of COL1A1 and MMP1 in UVA-irradiated HDFs}

Expression of COL1A1 mRNA, a member of group I collagen which include COL1A1 and COL1A2,
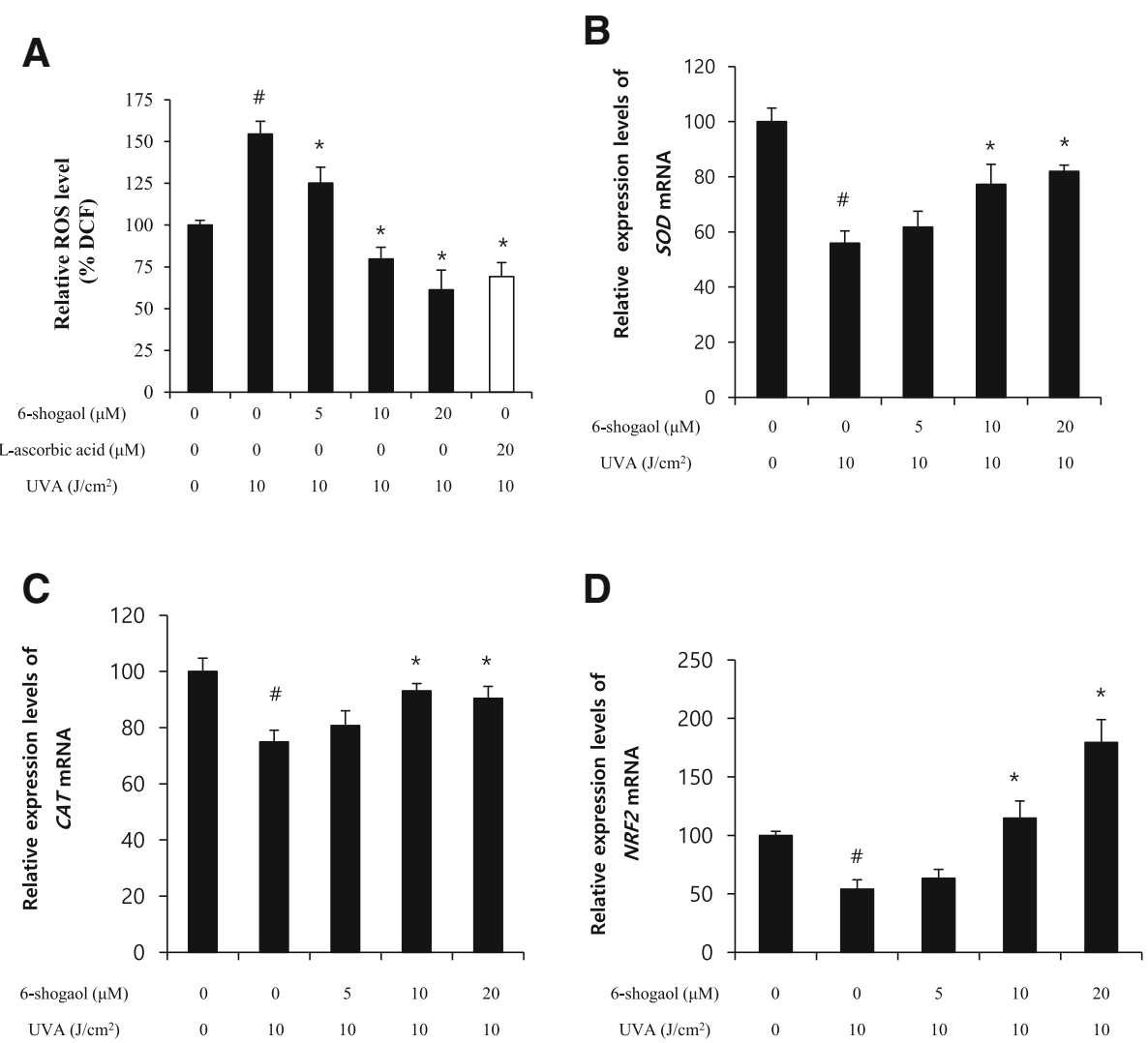

Fig. 3 Antioxidant effect of 6-shogaol in UVA-irradiated HDFs. a 6-Shogaol treatment scavenged ROS in a dose-dependent manner. 6-Shogaol treatment also upregulated the expression of $\mathbf{b} S O D, \mathbf{c} C A T$, and $\mathbf{d}$ NRF2 mRNA in a dose-dependent manner. The graphs are combined from three independent experiments (mean \pm S.D.). Student's $t$ test was conducted to determine statistical significance. ${ }^{*} p<0.05$ compared with UVAirradiated cells without 6-shogaol treatment; $\# p<0.05$ compared with negative controls that were not treated 6-shogaol or UVA irradiation 
decreased from 100 to $46 \%$ upon $10 \mathrm{~J} / \mathrm{cm}^{2}$ UVA irradiation, but in treatment with 6 -shogaol at 5, 10, and $20 \mu \mathrm{M}$, the reduction was only $55 \%, 74 \%$, and $81 \%$, respectively (Dalgleish 1997; Fig. 4b). In contrast, the expression of $M M P 1$, a gene that codes for an enzyme that degrades type I collagen, prominently increased from 100 to $543 \%$ upon $10 \mathrm{~J} / \mathrm{cm}^{2}$ UVA irradiation, but treatment with 6 -shogaol at 5,10 , and $20 \mu \mathrm{M}$ reduced these levels to $510 \%, 355 \%$, and $271 \%$, respectively (Fig. 4c).

\section{Discussion}

\section{Apoptotic signaling pathways}

Genes associated with apoptosis are divided into two main groups: anti-apoptotic and pro-apoptotic. Anti-apoptotic proteins such as $\mathrm{Bcl}-2$ and $\mathrm{Bcl}-\mathrm{xL}$ suppress apoptosis, whereas pro-apoptotic proteins such as Bax and Bak promote apoptosis (Han et al. 2008; Li et al. 1997). Under normal conditions, both pro-apoptotic and anti-apoptotic proteins are kept in balance in the form of dimers in the mitochondria. When the balance between them is disturbed by stimulation, such as by ultraviolet irradiation or oxidative stress, cytochrome c is released from the mitochondria into the cytoplasm, which in turn activates caspase 9 and caspase 3. Caspase 3 is directly activated by caspase 9 and then cleaves poly ADP-Ribose polymerase (a gene repair enzyme) and induces cell apoptosis (Kang et al. 2011). This study showed that 6-shogaol attenuates UVA-induced cell apoptosis through the downregulation of the apoptosis-related Bax, caspase 9, and caspase 3. In addition, the UVA-induced increase in the number of cells in sub-G1 phase, which is rare in a normal cell cycle, was reduced in a concentration-dependent manner after pre-treatment with 6-shogaol. Taken together, these data indicated that 6-shogaol has anti-apoptotic effects on HDFs.

\section{Antioxidant pathways}

UVA penetrates HDFs and induces ROS production, thereby destroying the balance of the skin's antioxidant defense system and damaging normal skin cells. These ROS are produced by the inflammation reaction of prostaglandins (PGs) biosynthesis and the metabolism of
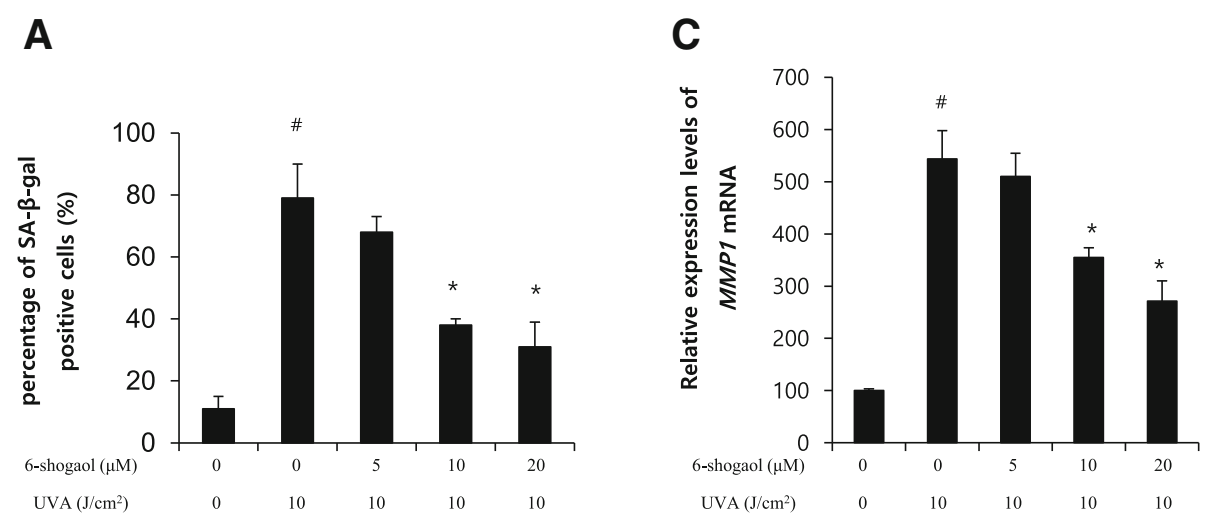

B

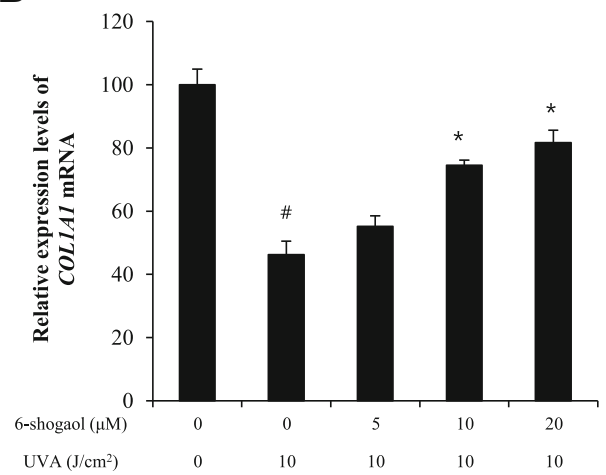

Fig. 4 Anti-aging effect of 6-shogaol in UVA-irradiated HDFs. a 6-Shogaol inhibited cellular senescence in a dose-dependent manner. 6-Shogaol also $\mathbf{b}$ upregulated the expression of COL1A1 MRNA and $\mathbf{c}$ downregulated the expression of MMP-1 MRNA in a dose-dependent manner. The graphs are a combination of three independent experiments (mean \pm S.D.). Student's $t$ test was conducted to determine statistical significance. ${ }^{*} p<0.05$ compared with UVA-irradiated cells without 6-shogaol treatment; \#p<0.05 compared with negative controls that were not treated 6-shogaol or UVA irradiation 
mitochondria-like organelles in normal cells (Okon and Zou 2015). However, most ROS are removed by antioxidant enzymes such as those encoded by GPX, CAT, and SOD or by antioxidants such as ubiquinone, vitamin $\mathrm{E}$, and vitamin C (Shindo et al. 1994; Urso and Clarkson 2003). Nrf2 is a transcription factor that regulates the expression of antioxidant enzymes in response to oxidative stress, such as those encoded by $S O D$, GPX, and CAT. SOD encodes for superoxide dismutase, a typical antioxidant enzyme that reduces oxidative stress by converting superoxide into hydrogen peroxide (Slater 1984; Zelko et al. 2002). CAT encodes catalase, which converts the $\mathrm{H}_{2} \mathrm{O}_{2}$ produced by SOD to $\mathrm{H}_{2} \mathrm{O}$ and $\mathrm{O}_{2}$ (Dickinson and Forman 2002). In this way, the antioxidant enzymes protect membrane and cytosolic components against cell damage caused by UV (Okon and Zou 2015). This study showed that 6-shogaol increases the expression of $S O D$ and $C A T$ mRNAs in a dose-dependent manner through the upregulation of NRF2 mRNA, thus upregulating the expression of antioxidant enzymes in response to oxidative stress. In addition, the elevation of ROS induced by UVA irradiation was ameliorated in a concentration-dependent manner by pre-treatment with 6-shogaol. Taken together, these data demonstrated that 6-shogaol can inhibit oxidation in HDFs.

\section{Anti-aging pathway}

Collagen, the most abundant protein in humans, is represented by 28 types. The most common ones present in the dermis are collagen type I comprising $80-85 \%$ and type III comprising 15-20\% (Dalgleish 1997; Stewart et al. 2006). Collagen is synthesized in the skin by fibroblasts, and the genes responsible for the production of collagen type I are COL1A1, which is located on chromosome 17 and encodes the $\alpha 1(\mathrm{I})$ chain, and COL1A2, which is located on chromosome 7 and encodes the $\alpha 2(\mathrm{I})$ chain. Type I collagen is considered to be the mature form and consists of a heterotrimer composed of two identical chains $\alpha 1$ (I) and one $\alpha 2$ (I); this protein is primarily responsible for the mechanical strength of tissues (Huerre et al. 1982; Stadelmann et al. 1998; Furth 1991). Matrix metalloproteases (MMPs) play a role in the degradation of collagen, particularly in aging skin. MMP-1 is known to be a main factor in age-associated diseases, including photo-induced skin wrinkling, and is highly associated with stress-induced premature senescence (Lee et al. 2012; Pittapruek et al. 2016). Therefore, MMP-1 is a biomarker of photoaging because its expression is responsible for extracellular matrix degradation in skin (Martin et al. 1990). In this study, pre-treatment with 6-shogaol inhibited MMP-1 mRNA expression and increased COL1A1 mRNA expression, suggesting that it has anti-aging effects.

\section{Conclusions}

This study investigated the potential of 6-shogaol as a natural cosmetic raw material by examining its anti-apoptotic, antioxidant, and anti-aging effects in HDFs.

First, the number of cells in the sub-G1 phase, which is rarely found in the normal cell cycle, decreased in a concentration-dependent manner after 6-shogaol pretreatment. Pro-apoptotic caspases 3 and 9 as well as the pro-apoptotic protein Bax decreased in a dose-dependent manner upon 6-shogaol treatment. This suggests that 6-shogaol inhibits the UVA-induced apoptosis of HDFs.

Second, ROS increased upon UVA irritation of HDFs was reduced by 6 -shogaol in conjunction with increased expression of $N R F 2$, which is a transcription factor that controls the expression of antioxidant enzymes during oxidative stress. In addition, the expression of $S O D$ and $C A T$, which encode for typical antioxidant enzymes, was increased. These results indicate that 6 -shogaol inhibits oxidation of HDFs induced by UVA.

Third, 6-shogaol increased the expression of COL1A1, which produces type 1 collagen in HDFs, and decreased the expression of $M M P 1$, an enzyme that degrades type 1 collagen; these effects promote collagen formation. In addition, a reduction in senescence of HDFs by 6-shogaol was observed.

Consequently, these results suggest the possibility of 6-shogaol as a natural cosmetic raw material preventing skin aging, through identified functions on the anti-apoptotic, antioxidant, and anti-aging effects in HDFs reported here.

\section{Abbreviations \\ BAX: BCl-2-associated X protein; CAT: Catalase; COL1A1: Collagen, type I, alpha 1; DCF-DA: Dichlorofluorescein diacetate; GPX: Glutathione peroxidase; $\mathrm{H}_{2} \mathrm{O}_{2}$ : Hydrogen peroxide; HDF: Human dermal fibroblast; MMP: Matrix metalloproteinase; $\mathrm{O}_{2}^{-}$: Superoxide anion; $\mathrm{OH}^{-}$: Hydroxyl radical; PBS: Phosphate-buffered saline; qRT-PCR: Quantitative real-time polymerase chain reaction; ROS: Reactive oxygen species; SA- $\beta$-gal: Senescence- associated beta-galactosidase; SOD: Superoxide dismutase; WST-1: Water- soluble tetrazolium salt}

\section{Acknowledgements}

Not applicable

\section{Funding}

There was no funding for this research article.

\section{Availability of data and materials}

Not applicable

\section{Authors' contributions \\ $\mathrm{HSH}$ and SA designed the study. KBK, JHJ, and ISA did all of the research such as experiments, data collection, and statistical analysis. HSH and YJK wrote the draft of the manuscript. All authors read and approved the final manuscript.}

Ethics approval and consent to participate Not applicable

Consent for publication Not applicable. 


\section{Competing interests}

Sungkwan An is the co-Editor-in-Chief, In Sook An and Jin Hyuk Jung are the Managing Editors, and Hyo Sun Han is an Editor of Biomedical Dermatology.

\section{Publisher's Note}

Springer Nature remains neutral with regard to jurisdictional claims in published maps and institutional affiliations.

\section{Author details}

'Department of Biological Engineering, Konkuk University, Seoul, Republic of Korea. ${ }^{2}$ Korea Institute of Dermatological Sciences, Seoul, Republic of Korea. ${ }^{3}$ Department of Beauty Yakson Care, Yeoju Institute of Technology, Yeoju-si, Gyeonggi-do, Republic of Korea. ${ }^{4}$ Department of Cosmetics Engineering, Konkuk University, 120 Neungdong-ro, Gwangjin-gu, Seoul 05029, Republic of Korea.

\section{Received: 21 September 2018 Accepted: 7 November 2018}

\section{Published online: 28 November 2018}

\section{References}

Bak MJ, Ok S, Jun M, Jeong WS. 6-Shogaol-rich extract from ginger upregulates the antioxidant defense systems in cells and mice. Molecules. 2012;17:8037-55.

Cha HJ, Kim YJ. Procyanidin B regulates matrix-metalloprotease 1 mRNA expression using JNK-AP1-TRE axis in normal human dermal fibroblasts. Asian J Beauty Cosmetol. 2015:13:761-5.

Dalgleish R. The human type I collagen mutation database. Nucleic Acids Res. 1997;25:181-7.

Dickinson DA, Forman HJ. Glutathione in defense and signaling: lessons from a small thiol. Ann N Y Acad Sci. 2002;973:488-504.

Furth JJ. The steady-state levels of type I collagen mRNA are reduced in senescent fibroblasts. J Gerontol. 1991;46:B122-4.

Han SI, Kim YS, Kim TH. Role of apoptotic and necrotic cell death under physiologic conditions. BMB Rep. 2008;41:1-10.

Huang HC, Chang SJ, Wu CY, Ke HJ, Chang TM. [6]-Shogaol inhibits a-MSHinduced melanogenesis through the acceleration of ERK and PI3K Aktmediated MITF degradation. Biomed Res Int. 2014. https://doi.org/10.1155/ 2014/842569.

Huerre C, Junien C, Weil D, Chu ML, Morabito M, Cong NV, et al. Human type I procollagen genes are located on different chromosomes. Proc Natl Acad Sci U S A. 1982;79:6627-30

Kang ES, Iwata K, Ikami K, Ham SA, Kim HJ, Chang KC, et al. Aldose reductase in keratinocytes attenuates cellular apoptosis and senescence induced by UV radiation. Free Radic Biol Med. 2011;50:680-8.

Kim J, Lee CW, Kim EK, Lee SJ, Park NH, Kim HS, et al. Inhibition effect of Gynura procumbens extract on UV-B-induced matrix-metalloproteinase expression in human dermal fibroblasts. J Ethnopharmacol. 2011;137:427-33.

Kim JS, Lee SI, Park HW, Yang JH, Shin TY, Kim YC, et al. Cytotoxic components from the dried rhizomes of Zingiber officinale Roscoe. Arch Pharm Res. 2008; 31:415-8.

Lee NK, Ku JE, Han HS. Cytoprotective and anti-inflammatory effects of 6-shogaol on human dermal fibroblasts. Asian J Beauty Cosmetol. 2017;15:367-76.

Lee YR, Noh EM, Han JH, Kim JM, Hwang JK, Hwang BM, et al. Brazilin inhibits UVB-induced MMP-1/3 expressions and secretions by suppressing the NF-KB pathway in human dermal fibroblasts. Eur J Pharmacol. 2012:674:80-6.

Li P, Nijhawan D, Budihardjo I, Srinivasula SM, Ahmad M, Alnemri ES, et al. Cytochrome $\mathrm{c}$ and dATP-dependent formation of Apaf-1/caspase-9 complex initiates an apoptotic protease cascade. Cell. 1997;91:479-89.

Ling $\mathrm{H}$, Yang $\mathrm{H}$, Tan $\mathrm{SH}$, Chui WK, Chew EH. 6-Shogaol, an active constituent of ginger, inhibits breast cancer cell invasion by reducing matrix metalloproteinase-9 expression via blockade of nuclear factor-kB activation. Br J Pharmacol. 2010;161:1763-77.

Martin M, el Nabout R, Lafuma C, Crechet F, Remy J. Fibronectin and collagen gene expression during in vitro ageing of pig skin fibroblasts. Exp Cell Res. 1990;191:8-13.

Okon IS, Zou MH. Mitochondrial ROS and cancer drug resistance: implications for therapy. Pharmacol Res. 2015;100:170-4.

Piao MJ, Kang KA, Kim KC, Chae S, Kim GO, Shin T, et al.

Diphlorethohydroxycarmalol attenuated cell damage against UVB radiation via enhancing antioxidant effects and absorbing UVB ray in human $\mathrm{HaCaT}$ keratinocytes. Environ Toxicol Pharmacol. 2013;36:680-8.
Pittapruek P, Meephansan J, Prapapan O, Komine M, Ohtsuki M. Role of matrix metalloproteinases in photoaging and photocarcinogenesis. Int J Mol Sci. 2016;17:868.

Shindo Y, Witt E, Han D, Epstein W, Packer L. Enzymic and non-enzymic antioxidants in epidermis and dermis of human skin. J Invest Dermatol. 1994; 102:122-4.

Slater TF. Free-radical mechanisms in tissue injury. Biochem J. 1984;222:1-15.

Stadelmann WK, Digenis AG, Tobin GR. Physiology and healing dynamics of chronic cutaneous wounds. Am J Surg. 1998;176(2A Suppl):26S-38S.

Stewart TL, Jin H, McGuigan FE, Albagha OM, Garcia-Giralt N, Bassiti A, et al. Haplotypes defined by promoter and intron 1 polymorphisms of the COLIA1 gene regulate bone mineral density in women. J Clin Endocrinol Metab. 2006;91:3575-83.

Urso ML, Clarkson PM. Oxidative stress, exercise, and antioxidant supplementation. Toxicology. 2003;189:41-54

Yoon Y, Bae S, An S, Choe YB, Ahn KJ, An IS. Effects of ultraviolet radiation on the skin and skin cell signaling pathways. Asian J Beauty Cosmetol. 2013:11:417-26

Zelko IN, Mariani TJ, Folz RJ. Superoxide dismutase multigene family: a comparison of the CuZn-SOD (SOD1), Mn-SOD (SOD2), and EC-SOD (SOD3) gene structures, evolution, and expression. Free Radic Biol Med. 2002:33:337-49.
Ready to submit your research? Choose BMC and benefit from:

- fast, convenient online submission

- thorough peer review by experienced researchers in your field

- rapid publication on acceptance

- support for research data, including large and complex data types

- gold Open Access which fosters wider collaboration and increased citations

- maximum visibility for your research: over $100 \mathrm{M}$ website views per year

At BMC, research is always in progress.

Learn more biomedcentral.com/submissions 